\title{
The Unique Badness of Hypocritical Blame
}

\author{
KYLE G. FRITZ \\ University of Mississippi \\ DANIEL J. MILLER \\ West Virginia University
}

\begin{abstract}
It is widely agreed that hypocrisy can undermine one's moral standing to blame. According to the Nonhypocrisy Condition on standing, $R$ has the standing to blame some other agent $S$ for a violation of some norm $N$ only if $R$ is not hypocritical with respect to blame for violations of $N$. Yet this condition is seldom argued for. Macalester Bell points out that the fact that hypocrisy is a moral fault does not yet explain why hypocritical blame is standingless blame. She raises a challenge: one must explain what is distinct about hypocritical blame such that the hypocritical blamer lacks the standing to blame, even if the arrogant or petty blamer does not. Of those writing on hypocrisy, only we offer a direct response to Bell's challenge. Recently, however, our account has come under criticism. We argue here that (1) our account can handle these criticisms and that (2) no other rival account adequately addresses Bell's challenge of explaining what is uniquely objectionable about hypocritical blame. Because answering Bell's challenge is a necessary component of any plausible account of the relationship between hypocrisy and standing, our account remains the best on offer.
\end{abstract}

Keywords: hypocrisy; blame; moral standing; hypocritical blame; equality of persons.

\footnotetext{
T $\mathrm{T}$ is widely agreed that hypocrisy can undermine one's moral standing to Lblame (Fritz \& Miller 2018; Isserow \& Klein 2017; Roadevin 2018; Todd 2019; Wallace 2010). According to the Nonhypocrisy Condition on standing, $R$ has the standing to blame some other agent $S$ for a violation of some norm $N$ only if $R$ is not hypocritical with respect to blame for violations of $N$.
}

Contact: Kyle Fritz<kgfritz@olemiss.edu>, Daniel Miller <daniel.miller2@mail.wvu.edu> 
While this condition is often taken for granted, it is seldom argued for. The fact that hypocrisy is a moral fault does not yet explain why hypocritical blame is standingless blame. As Macalester Bell issues the challenge:

People may, and frequently do, evince a wide variety of moral faults through their blame: they can show meanness, pettiness, stinginess, arrogance, and so on. But while people may manifest hypocrisy and other faults in their critical interventions, there is no reason to conclude that these faults always undermine a person's standing to blame. (2013: 275)

In other words, not all moral faults undermine one's standing to blame. In order to show that hypocrisy can, then, it is not sufficient to explain that hypocrisy is morally objectionable in some way. Rather, one must explain what is distinct about hypocrisy such that being hypocritical with respect to blame can undermine one's standing to blame, even if these other faults do not.

While all of the authors who maintain the Nonhypocrisy Condition offer an account of the morally objectionable nature of hypocrisy, nearly all fail to offer the explanation required to meet Bell's challenge in a clear and satisfying way. Indeed, only we offer a direct response to Bell's challenge (Fritz \& Miller 2018). Recently, however, our account has come under criticism, both directly from Cristina Roadevin and Patrick Todd, as well as indirectly from Jessica Isserow and Colin Klein. We argue here that (1) our account can handle these criticisms and that (2) no other rival account adequately addresses Bell's challenge of explaining what is uniquely objectionable about hypocritical blame. Because answering Bell's challenge is a necessary component of any plausible account of the relationship between hypocrisy and standing, our account remains the best on offer.

\section{The Dispositional Equality of Persons View}

We directly address Bell's challenge, offering a clear argument for why being hypocritical with respect to blame undermines the moral standing, or right, to blame. ${ }^{1}$ On our view, being hypocritical with respect to blame is a matter of having an unfair differential blaming disposition (UDBD) - having a disposition to blame others for a violation of some norm $N$ but lacking a disposition to blame oneself for violations of $N$ without having a justifiable reason for this differ-

1. We understand the moral standing to blame as a matter of having a non-defeated right to blame (2018). 
ence (2018: 122). ${ }^{2}$ In what follows, we will use the term "would-be hypocritical blame" as shorthand for having this type of UDBD. We will use the term "actual hypocritical blame" to refer to manifestations of this type of UDBD. It is not always clear how other writers are using their terminology. To avoid misrepresenting these authors' views, we will use the more generic term hypocritical blame to refer either to having the relevant disposition or to blaming hypocritically (where other authors may have their own account of what the latter comes to).

On our view, the reason why would-be hypocritical blame undermines one's standing to blame is that in having a UDBD, the hypocrite (implicitly) rejects the impartiality of morality and, consequently, the equality of persons with respect to blaming for violations of $N$, which is what grounds the right to blame for violations of $N$ in the first place. We present our argument as follows (2018: 125):3

1. If $R$ is hypocritical with respect to blame for violations of $N$, then $R$ has a UDBD with respect to violations of $N$.

2. If $R$ has a UDBD with respect to violations of $N$, then $R$ rejects the impartiality of morality with respect to violations of $N$.

3. If $R$ rejects the impartiality of morality with respect to violations of $N$, then $R$ rejects the equality of persons with respect to violations of $N$.

4. If $R$ rejects the equality of persons with respect to violations of $N$, then $R$ rejects the grounding that gives $R$ the right to blame $S$ for violations of $N$.

5. If $R$ rejects the grounding that gives $R$ the right to blame $S$ for violations of $N$, then $R$ forfeits the right to blame $S$ for violations of $N$. So,

6. If $R$ is hypocritical with respect to blame for violations of $N$, then $R$ forfeits the right to blame $S$ for violations of $N$.

Premise 1 follows from our understanding of what it means to be hypocritical with respect to blame. Premise 2 is rooted in a reasonable understanding of what the impartiality of morality requires: if one is unfairly disposed to blame differentially for a norm violation, one cannot accept that morality is impartial with respect to that norm violation. By having the hypocritical UDBD, one makes an

2. We do not use the abbreviation UDBD in our 2018 paper, but instead talk of DBDs more generally. Because unfair DBDs are the sort that undermine standing, we are concerned only with unfair DBDs, which we here call UDBDs for clarity.

3. We have modified the argument for clarity by replacing "DBD" with "UDBD." Given that the purpose of our 2018 paper is to show how being hypocritical with respect to blame undermines standing, we have also clarified premise 1 and the conclusion to refer to "blame for violations of N." For a fuller defense of the argument, see Fritz \& Miller (2018: 126-127). 
exception of oneself, implying that morality applies differently to one. But as premise 3 expresses, this exception-making involves an implicit rejection of the claim that we are all morally equal as persons.

The moral equality of persons, like the impartiality of morality, is a cornerstone of morality. It is also a cornerstone of our argument, as we hold that the right to blame is rooted in the moral equality of persons. Our argument for this claim relies on two key steps: first, that there are certain rights that every person has (among these the right to blame), and second, that the best explanation of why persons have these rights is that they have them in virtue of their personhood.

We take it as a fundamental principle of ethics that every person has certain basic obligations and rights: we have obligations to respect each other, for instance, and corresponding rights to be respected. If persons have any rights at all, and such rights are equally possessed by all persons, then the equal possession of basic moral rights among persons can be grounded only in something that explains the relevant equality. The best explanation for the equal possession of these basic moral rights is precisely that we are all persons, each of us having equal moral worth.

Yet we hold that the right to blame others is a basic moral right; more precisely, we each have the defeasible right to hold others accountable by blaming for norm violations, and this is in virtue of being a person. ${ }^{4}$ Our reasoning for this is slightly less direct; we see no grounding for the right to blame other than our equal, shared personhood. If the right to blame is basic, as we maintain, then having that right does not depend upon anything else other than being a person.

Any objection to the effect that there may (for all we know) be some alternative grounding for the right to blame would require an explanation that is at least as plausible as the equality of persons. As far as we are aware, no alternatives have been offered. Yet we will examine two potential alternatives. By reflecting upon these alternative suggestions for what might ground the right to blame, we will not only eliminate these alternatives as candidates for this role, we will actually find a further, positive reason to support our view.

One might suggest that the right to blame is grounded, not merely in being a person, but in being a person with a virtuous character. We often either dismiss or rebuke those who are less than virtuous when they blame, as though blaming involves at least the pretense that one is taking the moral high ground, adopting

4. Importantly, because this right is defeasible, this view does not entail that every person has the right to blame anyone in any situation. For example, the fact that $S^{\prime}$ s moral fault is none of $R^{\prime} \mathrm{s}$ business may undermine $R$ 's right to blame $S$. Although we sometimes write loosely of "lacking a right to blame," this should be understood to mean that one's right to blame (with respect to some norm violation) is defeated. 
a condescending attitude, or implicitly demanding respect. Perhaps those who lack a virtuous character are not entitled to such a position, so it is false that the right to blame is a basic right all persons have.

This suggestion may seem plausible in part because lacking a virtuous character and lacking the right to blame often go hand in hand. The less than virtuous person may often be a hypocritical blamer, having done what he blames others for without being disposed to blame himself for it. But lacking a virtuous character and lacking the right to blame can come apart. For example, in January of 2019, an electrical fire caused a power outage to the Metropolitan Detention Center in Brooklyn, and the warden did not restore power for a week. Prisoners were left to suffer through temperatures as low as $2^{\circ} \mathrm{F}$ (Correal \& Goldstein 2019). These prisoners, even if guilty of criminal activity, have the right to become angry at the warden. Lacking virtue does not entail that one lacks the right to blame for anything.

Alternatively, one might suggest that the right to blame someone derives, not merely from being a person, but from being in a special relationship with that person. Friendships, romantic relationships, and business relationships are partly constituted by various norms and expectations (see Scanlon 2008: Ch. 4). These may include expectations that one will provide help to the other in times of need, that one will keep confidences, that one will in general seek to further the interests of the other (rather than their harm), and so on. When one person in a special relationship wrongs another by violating or failing to meet one of these expectations, we do not believe that just anyone has the moral standing to respond to the wrongdoer with blame. Rather, it is the person who was wronged who is (all else equal) entitled to respond with blame.

This suggestion has some initial plausibility, since a person's right to blame for some fault seems to depend upon the fault's being that person's business. Being a member of a special relationship who was wronged by the other member of that relationship quite straightforwardly makes it one's business. Ultimately, however, this suggestion cannot be correct, since we at least sometimes have the standing to blame people with whom we have no special relationship. ${ }^{5}$ If a stranger shoves you out of his way while walking down the street, for example, you have the right to blame him for doing so. But you have no special relationship with that person; there are no special norms or expectations that he has violated in wronging you.

One might respond by pointing out that your right to blame the stranger still depends upon a special relationship - the moral relation. As Scanlon writes, "morality requires that we hold certain attitudes toward one another simply in lem.

5. See George Sher's (2013) critique of Scanlon's view for an extended discussion of this prob- 
virtue of the fact that we stand in the relation of 'fellow rational beings'" (2008: 140). You stand in the moral relation with all fellow persons in virtue of your shared personhood, and there are certain norms and expectations that you hold for your interactions with every other person, such as treating each person with respect, not harming others, helping them when it is easy, etc. (2008: 140). It is in virtue of this relationship, one might argue, that you have the (defeasible) standing to blame strangers.

Perhaps this is right, but if so, it would only offer further positive support for our view. For, what this response amounts to is the idea that we have the defeasible right to blame anyone (including strangers) because of a relationship that we have with everyone that is grounded merely in the fact that we are all persons. So, in a sense, we want to hold that the defeasible right to blame others is grounded in a kind of relationship. But the relationship is not a special one that only some of us bear to one another. Rather, it is the relationship we have with everyone merely in virtue of the equality of persons.

By rejecting the equality of persons with respect to some norm violation, one rejects the very thing that grounds that right, and thereby implicitly forfeits the right to blame for violations of that norm. This holds whether the blame in question is expressed to the agent blamed, expressed to a third party, or is private in nature (such as engaging in an internal diatribe or experiencing reactive moral anger). Furthermore, this holds prior to any such blame, in virtue of one's UDBD. That one's blame would be hypocritical, given one's UDBD, explains why one lacks the standing to blame.

We provide a powerful explanation for why would-be hypocritical blame undermines moral standing with respect to some norm violation, thereby answering Bell's challenge. Arrogant and petty blame as such need not involve UDBDs, so they do not involve an implicit rejection of the very grounding of the right to blame. Thus our view shows what any account of the relationship between hypocrisy and standing must show: what is exceptional about would-be hypocritical blame such that it undermines moral standing.

As we will argue, we provide the only plausible extant answer to Bell's challenge. In fact, many writers on hypocrisy and hypocritical blame fail even to address the challenge. Without an answer to this challenge, their views cannot stand as plausible accounts.

\section{Wallace's Equality of Persons View}

We are partly indebted to R. Jay Wallace (2010), who understands hypocritical blame in terms of unfair exception-making: the hypocritical blamer engages in blaming others for faults that he has himself committed without also subjecting himself to 
blame. Wallace asks, "why exactly is it that we lack standing to blame others for things that we do or have done for ourselves?" (2010:318). Like the answer we offer, Wallace's answer appeals to the fact that the hypocritical blamer violates the principle of the equality of persons. We summarize Wallace's view as follows:

The hypocritical blamer shields herself from the moral criticism involved in blame while not doing the same for others. Since we all have an interest in being protected from moral criticism, when the hypocrite blames others for faults similar to those for which she is also blameworthy she treats others' interests as less important than her own. In so doing, she violates the principle of the equality of persons that is fundamental to morality. (Fritz \& Miller 2018: 123)

While we agree that Wallace has hit upon what is distinctively objectionable about the hypocrisy involved in hypocritical blame, this does not, on its own, answer the challenge Bell offers. In order to do so, one must answer a further question (indeed, Bell 2013 has Wallace in mind here): why does the fact that hypocrisy is distinctively objectionable in this way imply that the hypocritical blamer lacks the standing to blame? Wallace's explanation does not go far enough; it is still missing a step. But as explained above, this is precisely where our account bridges the gap: the would-be hypocritical blamer implicitly rejects the equality of persons, which is itself the ground of the moral right or standing to blame. In rejecting the former, one forfeits the latter.

There is an additional respect in which Wallace's account is incomplete. Wallace's explanation depends upon the fact that blame often has negative effects (e.g., social disapproval), and that we all have an interest in being protected from such effects (2010: 328). But if so, this seems to imply that Wallace's explanation is limited to "cases in which the blamed is aware of or impacted by the blame in some way" (Fritz \& Miller 2018: 124). Consequently, Wallace's explanation cannot account for instances of private hypocritical blame or other instances of hypocritical blame where the agent blamed is not impacted by the blame. So, even if Wallace's explanation did answer Bell's challenge, it would only do so with respect to certain kinds of hypocritical blame. Because our explanation does not rely on the impact that blame might have for the agent blamed, but rather on how UDBDs involve an implicit rejection of the equality of persons, it is not limited in the way that Wallace's purported explanation is.

\section{Roadevin's Reciprocity View}

Cristina Roadevin (2018) claims to offer an account of why hypocritical blame 
undermines the standing to blame that is rooted in the hypocritical blamer's failure to honor the reciprocal nature of morality. ${ }^{6}$ Unfortunately, although she engages with Bell's paper, Roadevin neither directly addresses nor meets Bell's challenge.

Like we do, Roadevin understands the hypocritical blamer as making an exception of himself without good reason (2018: 143), and she thinks that the wrongness of hypocritical blame lies partly in the hypocrite's attitudes toward his own wrongdoing (2018: 145). Similarly, she understands standing as a right (2018: 137). ${ }^{7}$ Unlike we do, however, she limits herself to only explaining why the hypocritical blamer lacks the standing to express blame (2018: 138, n. 3), and she is largely concerned with second-personal overt blame rather than third-personal cases (2018: 141). By limiting the scope of her view so narrowly, Roadevin presents an incomplete view and limits the power of her explanation.

Roadevin builds her view around the case of Harvey and Laura. Laura has an affair with Harvey's best friend and lies about her infidelity to Harvey. Yet Harvey has also cheated on Laura in the past without apologizing (Roadevin 2018: 137-138). As Roadevin tells the case, Harvey hypocritically blames Laura for lying about her infidelity. ${ }^{8}$ Roadevin argues that he consequently lacks the standing to blame Laura for her infidelity, offering the following explanation:

What undermines Harvey's standing to blame Laura is not the fact that he is guilty of the same thing but the fact that he culpably fails to observe, criticize, and scrutinize his own moral faults while demanding that others do. So the badness of hypocrisy can be best explained by a failure of reciprocity. Why does this typically undermine standing? In blaming Laura, Harvey is expecting an apology from her; however, Harvey himself owes Laura an apology. As a matter of justice, he needs to clear himself of his "moral debt" before he can be in a position to demand an explanation from Laura regarding her moral faults. (2018: 148)

6. Though we use the broader term "hypocritical blame" here, Roadevin writes as though it is the actual hypocritical blaming that undermines the blamer's standing to blame (2018: 144). This seems to imply that the hypocritical blamer's standing is undermined only after blaming, and not prior to it. One advantage of our dispositional view is that it allows one to explain why an agent might lack standing prior to blaming hypocritically.

7. However, Roadevin sometimes fails to distinguish between the claims that the hypocrite lacks the standing or right to blame, that the hypocrite should not blame, that the hypocrite's blame would be inappropriate, and that the hypocrite's blame would be unjustified (2018: 137-140). These claims are not obviously equivalent.

8. It is unclear whether Roadevin intends that Harvey be hypocritical with respect to lying or with respect to infidelity. Harvey may well be hypocritical with respect to infidelity, but if he never lied about his infidelity to Laura, he is not also hypocritical with respect to lying. We will ignore this complication here and assume that Harvey and Laura are guilty of violating the same norm. 
According to Roadevin, hypocritical blame is uniquely bad because it is a failure of reciprocity, and morality is inherently reciprocal: "the moral interaction between us also requires that we pay attention to our own faults and change our behavior, especially if we want our demands to be taken seriously when we ask others to answer to us" (2018: 147). This is similar to the explanation provided by Duff (2010) for why hypocritical blame undermines standing.

This failure of reciprocity is a different sort of fault than those involved in arrogant or petty blame. The hypocritical blamer expects the person he blames to apologize but has not discharged his own obligation to apologize. But in the spirit of Bell, one can ask both Roadevin and Duff, "Why does a failure to reciprocate undermine one's standing to blame? Why must one clear one's moral debt before one can be in a position to blame others?" Roadevin's explanation as it stands does not go far enough.

At times, Roadevin suggests that no more needs to be said. She writes, "The main problem with [the hypocrite's] blame is that he fails to see and understand something he should see and understand. He fails to see he is doing something he has no right to do" (2018: 147). Yet Roadevin has already assumed here that the hypocritical blamer lacks the right to blame without explaining why. Clearly the explanation cannot be that the hypocritical blamer lacks the right to blame because he fails to see that he lacks the right to blame.

At other times, however, Roadevin seems to implicitly rely on the very explanation that we have already offered. She claims that the hypocritical blamer's failure to critically engage with his own behavior "shows that he does not understand what is morally significant for our moral interactions - that is, that we have to live by the same moral standards we hold others to" (2018: 146). This sounds remarkably close to the impartiality of morality and the equality of persons, which we appeal to as the foundation of the standing to blame. On our view, the impartiality of morality means that everyone is subject to certain basic rights and obligations, and rejecting this requires rejecting the moral equality of persons. But the right to blame is grounded in the equality of persons. The result is that Roadevin's explanation is incomplete, and yet our argument provides the most salient way to supplement it.

Regardless, Roadevin rejects "equality of persons" views such as Wallace's and ours because she thinks it is possible for one to hypocritically blame while respecting a person as having equal interests (2018: 145). As an illustration, she alters the case of Harvey and Laura, supposing that Harvey has forgotten that he was unfaithful to Laura years ago even as he blames her for her infidelity (2018: 145-146). Roadevin imagines that Harvey fully respects Laura's interests as important as his, even though he makes an exception of himself.

Presumably Roadevin frames her objection in terms of respecting interests because Wallace explains his view in these terms. It is unclear exactly what 
Roadevin means by "respecting interests," however. On a weaker understanding, it may merely involve Harvey caring that things go as well for Laura as they do for him. But then it is possible for Harvey to respect Laura's interests even if he has a UDBD. Since our view concerns dispositions, it allows that Harvey can respect Laura's interests as equal in this sense while nevertheless being unfairly disposed to blame her and not himself for infidelity.

If Roadevin means something stronger, however, such as Harvey actually regarding Laura as on par with himself morally speaking, then this is incompatible with having a UDBD. But then everything hinges on a missing detail: Harvey's current dispositions regarding self-blame for infidelity. Harvey may have forgotten his infidelity, yet still be unfairly disposed to blame Laura and not himself for similar wrongdoing. If so, then he thereby necessarily (albeit implicitly) rejects the impartiality of morality as well as the equality of persons with respect to that wrongdoing. In that case, it is conceptually incoherent to say that he regards Laura as morally equal while having a UDBD. On the other hand, if Harvey is now disposed to blame both himself and Laura for similar wrongdoing, but simply fails to blame himself because he forgot he was guilty, then he is not a hypocritical blamer on our view. He lacks a UDBD and retains the standing to blame Laura for her infidelity (Fritz \& Miller 2018: 130).

So whether Harvey can hypocritically blame Laura while equally respecting her interests in Roadevin's case depends on how we understand these interests. On a weaker reading, "respecting interests" is compatible with having a UDBD, and on a stronger reading it is not. If Harvey has a UDBD, he cannot equally respect Laura's interests in the stronger sense, but if he does not, then he can respect such interests because his blame is not hypocritical at all. Even if Roadevin creates a problem for Wallace's equality of persons view, there is no good reason to reject our view or the equality of persons as the foundation of the standing to blame. In fact, this equality is the deeper explanation needed to properly explain why a failure of reciprocity might undermine standing.

One last remark may push Roadevin even closer to adopting our view. She holds that whether an individual is hypocritical in blaming another "will depend on how he responds to her when he is confronted" (Roadevin 2018: 147). Yet we can imagine that an individual is never confronted. This would seem to imply that someone can avoid being hypocritical (and thereby preserve his own standing) simply by avoiding interactions with someone who might confront him. It would be bizarre if Roadevin intended to claim that such an individual was not hypocritical after all, as though being guilty for this moral fault depends upon whether someone calls him out for it. Presumably, Roadevin wants to adopt a dispositional sort of account like ours, where being hypocritical with respect to blaming depends on how one is disposed to behave toward oneself and others and what attitudes one is disposed to have towards oneself and others. But if she 
does this, while adding the necessary supplement of the equality of persons to answer Bell's challenge, there is very little daylight between an altered version of Roadevin's view and our own.

\section{Isserow and Klein's Moral Authority View}

Jessica Isserow and Colin Klein attempt to uncover "what hypocrites have in common, or what is distinctively bad about them" (2017: 191). While this is not explicitly tackling Bell's challenge, it is closely related. One might think that whatever is distinctively bad about hypocrisy could explain why hypocritical blame, but not arrogant or petty blame, is standingless blame.

On their view, "hypocrites are persons who have, by mismatch between judgments and actions, undermined their claim to moral authority" (2017: 193, emphasis original). For Isserow and Klein, an agent's moral authority is "a kind of standing that they occupy within a particular moral community -a status that is intimately tied up with their capacity to (1) warrant esteem, and (2) bestow (dis)esteem on others" (2017: 193). Thus, when moral authorities exercise condemnation, their condemnation has an illocutionary force for their communities (2017: 198), and this is what the hypocrite's condemnation lacks in virtue of the mismatch. ${ }^{9}$

Whatever the merits of Isserow and Klein's account, one might protest that moral authority and moral standing are distinct. After all, Isserow and Klein describe their target as "social standing" (2017: 200), so it seems they are simply not interested in addressing Bell's challenge. Ultimately, we agree. But crucially, Isserow and Klein set themselves up as if they were in the same conversation, discussing Wallace as among their "rival accounts" (2017: 193) and sometimes referring to standing as "entitlement" (2017: 202). This is a mistake. Bell's challenge concerns a moral right, and having a moral right to blame need not be connected with the illocutionary force of one's speech act. After all, one can have or lack the right to privately blame, but only overt expressed blame can have illocutionary force.$^{10}$ Additionally, one might have the moral right to feel or express resentment, even if one's resentment lacks illocutionary force. Finally, having a

9. Isserow and Klein are careful to emphasize that a hypocrite need not have actually functioned as a moral authority. A hypocrite is rather one who has lost his claim to moral authority (2017: 205). One might say that, on Isserow and Klein's view, the hypocrite is (whether he was previously a moral authority or not) disqualified to function as a moral authority because of the relevant mismatch.

10. This reveals that Isserow and Klein's view has the same limitation that Wallace's and Roadevin's views have. Interestingly, Patrick Todd has the complimentary shortcoming. He is concerned only with the right to feel blame and does not aim to discuss the right to express blame (2019: 350). 
moral right to blame need not require one's having a special position of moral authority in the community.

Ultimately, then, Isserow and Klein may explain why hypocrites lack a place of moral reverence in society and why we do not take their criticisms or condemnations seriously, but they cannot answer Bell's challenge and explain why hypocrites lack the moral right to either express or even feel blame for those offenses with respect to which they are hypocritical.

Though they do not answer Bell's challenge, Isserow and Klein raise important worries for views with features similar to ours, so we should address some of them here. The first worry concerns dispositional accounts of hypocrisy. Isserow and Klein maintain that "many accounts have . . gone astray by assuming that hypocrisy amounts to a kind of settled disposition" (2017: 193). In particular, some such accounts fail to adequately capture

everyday attributions of hypocrisy; for these certainly do not appear to be restricted to those with a settled disposition to take morality insufficiently seriously. ... It seems implausible to us that hypocrisy as it operates in day-to-day life amounts to a full-fledged character trait. (2017: 216)

If Isserow and Klein simply maintain that one can be a hypocrite with respect to some norm without having a bad character, we can happily agree. While we analyze a hypocritical blamer as one who has an unfair differential blaming disposition, we are not committed to the view that such dispositions must be settled character traits. Rather, like other dispositions, UDBDs can be quite finely grained, and need not have any lengthy temporal duration. One may be disposed to become angry at others but not oneself only when it comes to a very particular fault. One may also slip into hypocritical blame when in a particularly defensive or vulnerable mood, but quickly snap out of it when shown the error of one's ways.

Furthermore, a dispositional account of hypocritical blame has distinct advantages. It is able to explain why would-be hypocritical blamers lack the standing to blame before they engage in actual hypocritical blame, since the hypocrite may nevertheless be disposed to blame others but not himself (and thus already implicitly reject the equality of persons). A dispositional account of hypocritical blame can also explain how a hypocritical blamer can regain the standing to blame, even if he never addresses a past fault, perhaps since he forgot about it (Fritz \& Miller 2018: 129ff.). If the hypocritical blamer comes to have the right dispositions toward himself and others with respect to the relevant norm (such that he would appropriately address his fault were it to be brought back to memory), then he regains the standing to blame for violations of that norm. 
Isserow and Klein raise an additional objection for views that explain the hypocrite's lack of standing by appealing to the hypocrite's rejection of the equality of persons. They focus on Wallace's view in particular:

\begin{abstract}
Although [Wallace's] account works naturally for moral communities who think that people are fundamentally equal from a moral point of view, charges of hypocrisy arise even in societies with no such commitment. The seventeenth-century Catholic Church, for example, was hardly egalitarian-yet audiences at the time recognized Tartuffe as a hypocrite all the same. Hence, even people who are not committed to something like the equality of persons can clearly recognize and condemn hypocrisy. This is something that Wallace's account seems to have trouble accommodating. (Isserow \& Klein 2017: 215)
\end{abstract}

While Wallace focuses on hypocritical blame, his account does not restrict him from acknowledging other types of hypocrites or recognizing that hypocrisy is broader than hypocritical blame. At the outset, Wallace writes, "I shall try to distinguish the objectionable form of hypocrisy, which I shall refer to as hypocritical moral address, from other forms of hypocrisy that are not objectionable in the same way" (2010: 308, emphasis added). Wallace is concerned with isolating one kind of hypocrisy that is particularly morally objectionable. Isserow and Klein themselves recognize this intentional focus on Wallace's part (2017: 213). Likewise, we acknowledge other kinds of hypocrisy, but restrict our discussion to a sort of "exception-seeking" hypocrite who rejects the equality of persons. ${ }^{11}$

Consider Tartuffe, who is mentioned as a problematic example of hypocrisy for such accounts. Tartuffe "pretends to be pious for reasons of self-advancement. His hypocrisy does not consist in a single bout of inconsistency (of the relevant sort), but in a rather extensive pattern of deception" (2017: 210). Neither Wallace nor we need to deny that there is a type of hypocrisy that involves false pretense. Thus, even a society that rejects the equality of persons might be able to "recognize and condemn" this sort of hypocrisy.

If this is right, Isserow and Klein cannot be criticizing Wallace (and others) for their inability merely to recognize and condemn other sorts of agents that may

11. We write that other types of hypocrites "do not count as hypocrites in the way we discuss hypocrites here" and that, of the kinds of hypocrites listed by Bell (2013), "the third kind Bell describes ('exception-seeking hypocrites') is the closest to displaying the kind of hypocrisy that we believe to undermine the standing to blame" (2018: 135, n. 8, emphasis added). Nevertheless, we are guilty of a misstep when we write that "the hypocrite is willing to blame others for faults but unwilling to blame herself for similar faults" (2018: 121) and "hypocrisy fundamentally involves the nature of an agent's disposition to blame because it reflects how the agent regards herself and others" (2018: 122). Instead, given that we are largely focused on offering a response to Bell's challenge, our account of hypocrisy should be restricted to being hypocritical with respect to blame. 
count as hypocrites. It seems that their criticism must be that accounts that explain undermined standing of hypocritical blamers by appealing to the equality of persons cannot in a unified way explain the undermined standing of other types of agents that Isserow and Klein recognize as hypocrites. This is because it is one thing to be able to recognize and condemn the various moral faults of these agents, and quite another to maintain that all such agents lack standing because of these faults. But, we do not wish to commit ourselves to the view that all kinds of hypocrites lack the standing to blame, and neither does Wallace. Rather, we both aim to offer an account of why certain types of hypocrites (i.e., hypocritical blamers) lack the standing to blame in virtue of rejecting the equality of persons. But hypocrites like Tartuffe are not hypocritical blamers. Tartuffe may be guilty of deception and false pretense, but we maintain that he does not actually blame others for such violations, nor is he even disposed to do so. Rather, he merely pretends to blame. He does not care about the norms he violates or whether others violate them, and he experiences no reactive attitudes in response. Since we are concerned with why hypocritical blamers lack the standing to blame, and deceptive hypocrites like Tartuffe are not even disposed to blame, we have a principled reason for holding that deceptive hypocrites do not lack the standing to do what they are not even disposed to do. ${ }^{12}$

While Isserow and Klein have offered a convincing case for why all hypocrites may lack a claim to a special kind of moral authority (i.e., one that paradigmatically involves esteem), there simply is no plausible case that all types of hypocrites lack the moral right to feel or express anger or indignation. Consider a weak-willed agent, such as a PETA advocate who occasionally eats bacon (cf. Isserow \& Klein 2017: 20off.). She feels awful afterward and blames herself, sincerely desiring never to eat bacon again, and she admits to others that she is weak-willed and sometimes falls short of her own moral ideals. This agent has a mismatch that makes her hypocritical according to Isserow and Klein, so she apparently lacks the relevant moral authority (2017: 201-202). Yet, this weak-willed agent does not make an exception of herself or reject the equality of persons; she is disposed to hold herself to the same standards to which she holds others. ${ }^{13}$ As a result, we see no reason why such an agent, even if hypocritical, lacks the moral right to feel or express anger or indignation in response to others eating meat. And our account is no worse for the wear if it lacks an implication that is

12. Benjamin Rossi (2018) has recently criticized our view on similar grounds, arguing that we cannot explain why all types of hypocrites lack the standing to blame. We defend against Rossi's criticism in more detail in Fritz and Miller (2019). In our response, we point out that hypocrites like Tartuffe may lack standing in a counterfactual sense: if they were disposed to blame, they would (supposing they were still hypocritical) lack the standing to do so.

13. We are not even inclined to think of such a weak-willed blamer as hypocritical at all, but we set aside this point here. 
plausibly false (i.e., that all the types of agents that Isserow and Klein count as hypocrites lack standing).

Finally, Isserow and Klein claim that

The blame-centered account also struggles with cases that do not involve two people. As noted above, countries and organizations can accuse and be accused of hypocrisy. Yet it is not at all obvious that nations, corporations, and political parties have reactive attitudes, or that they are the proper targets of reactive attitudes, or even that they are capable of the kinds of propositional attitudes that Wallace's account requires. (2017: 215)

Crucially, Isserow and Klein's account has an advantage here only if there are group agents that can make pronouncements and act (or fail to act) in certain ways. And, if there are such group agents, then they will plausibly also be capable of relevant analogues of blaming attitudes, such as holding responsible, punishing, and other forms of sanction. But then accounts like Wallace's and our own plausibly can account for the hypocrisy of group agents. If group agents can act, make pronouncements or maintain judgments, fail to behave according to them, and so on, then presumably such group agents will also be able to make unfair exceptions of themselves, thus implicitly rejecting the moral equality on which their right to hold responsible rests.

\section{Todd's Bedrock View}

Like the above authors, Patrick Todd (2019) maintains that hypocritical blame undermines an agent's standing to blame. ${ }^{14}$ However, Todd restricts himself to what he calls the "basic moral standing to blame," which is the standing to "feel blame" rather than to "express blame" (2019: 350). In contrast, Wallace, Roadevin, and Isserow and Klein are focused on overt blame. In narrowing the question in this way, Todd risks shifting the topic or not engaging with interlocutors on their terms.

Even with this restriction, Todd maintains that there is no explanation of why the would-be hypocritical blamer lacks the basic standing to blame. In addressing the question, Todd answers, "he just does" (2019: 371). In other words, it is a bedrock moral fact that would-be hypocritical blame undermines one's standing to blame. It is worthwhile to restate Bell's more specific challenge here:

14. Like we do, Todd clearly maintains that would-be hypocritical blame undermines the standing to blame (2019: 348 ). 
other types of faults (e.g., meanness, pettiness, arrogance) do not undermine an agent's standing to blame. So, what is so special about hypocrisy such that wouldbe hypocritical blame does? Todd does not address this more focused challenge; indeed, if Todd's view is correct, then the challenge simply has no answer.

Todd's stance depends partly on his rejection of our answer to Bell's challenge, claiming that it proves too much. He highlights, as we acknowledge, that certain inconsistent blamers also implicitly reject the equality of persons, and therefore lack the standing to blame for the same reason that would-be hypocritical blamers do. We describe Olivia, who is enamored with Paige. Although Olivia is disposed to blame herself and others for lying, she is not disposed to blame Paige for lying given how enamored she is with Paige (2018: 132). Because Olivia has a UDBD with respect to blaming for violations of the norm against lying, she implicitly rejects the equality of persons with respect to violations of this norm and thereby forfeits her right to blame for lying.

Todd sees this as a fatal flaw. ${ }^{15}$ In his imagined case, a terrorist responsible for the 2016 attack on Pulse nightclub in Orlando attempts to deflect the blame of a US citizen by pointing out that the citizen is disposed to blame inconsistently. Whereas people in the US are disposed to blame terrorists for attacks in Paris and Orlando, they are not so disposed to blame terrorists who perpetrate attacks in Turkey throughout 2016. According to Todd, we are committed to the claim that such US citizens lack the standing to blame terrorists for any of their attacks - whether in Orlando, Paris, or Turkey - because they are not consistently disposed to blame all these terrorists.

We will argue that Todd is too hasty in dismissing our view. Once we look at the details of Todd's case and our view, it becomes far less clear whether our view really implies that the inconsistent blamer Todd describes lacks the standing to blame all such terrorists, or that it has the fatal flaw Todd suggests.

\subsection{Types of Inconsistent Blamers}

Importantly, we recognize two different types of inconsistent blamers (Fritz \& Miller 2018: 132-133). The first type, which we call Type A, is inconsistent with respect to blaming for violations of $N$ due to a UDBD with respect to violations of $N$. The second type, which we call Type B, is inconsistent with respect to blaming, but not due to any underlying general reason concerning how she regards persons. Her inconsistency is due to other factors: perhaps she is forgetful, inattentive, tired, distracted, unaware, etc. As with hypocritical blame, we

15. What Todd finds clearly objectionable others might not. Notably, Cohen suggests that the force of $t u$ quoque is related to inconsistency: "Suppose $A$ and $B$ have both committed the same crime, but I indignantly condemn $A$ only. Isn't my condemnation of $A$ suspect, unless I can supply a pertinent distinction between $A$ and $B$ ?" (2012: 138). 
can make a distinction between would-be inconsistent blamers and actual inconsistent blamers. Type A inconsistent blamers are either would-be or actual inconsistent blamers in virtue of having a UDBD. Type B inconsistent blamers are either would-be or actual inconsistent blamers whose inconsistency does not result from a UDBD, but from some other factor. ${ }^{16}$

We argue that Type A blamers lack the standing to blame for violations of $N$ for the same reason that the would-be hypocritical blamers do. Type B blamers, however, do not have any disposition that involves an implicit rejection of the equality of persons with respect to violations of $N$, and so do not lose standing on that basis. ${ }^{17}$

Are the inconsistent blamers in Todd's case Type A or Type B blamers? The case lacks sufficient detail for us to answer. While western news media covers terrorist attacks, they did not cover attacks in Turkey with the depth and attention that they did the Paris or Orlando attacks. This leaves open the possibility that many US citizens were simply unaware of the issue or of how devastating the attacks were (perhaps culpably, though this is a separate issue). For all we are told, then, the inconsistent blamers Todd describes might be of Type B. If so, their standing would not be undermined, since they are not inconsistently blaming as a result of some UDBD.

Of course, Todd is free to stipulate that the inconsistent blamers in his case are of Type A. But this raises two further questions: Is it so counterintuitive or unacceptable that Type A blamers lack the standing to blame the terrorists for their attacks? And how common are such blamers? These are

16. We will use "inconsistent blamer" generally throughout this section, though the context of various passages should be sufficient to clarify whether the individual in question is actually blaming.

17. Todd is aware of this distinction, yet he claims, "we can see that it is no part of having the standing to blame that one is perfectly disposed to exercise that standing fairly" (2019: 370). While we never claim that one must be so perfectly disposed, the following passage may be the source of some confusion: "Though [the Type B blamer's] blame is inconsistent, this particular type of inconsistency does not arise from any differential blaming dispositions. He does not reject the impartiality of morality ..." (2018: 133). Although we are not sufficiently clear here, the context of this passage makes it clearer that what is crucial is that this second type of inconsistent blamer does not have an unfair DBD, or UDBD, terminology not adopted in that paper.

Shortly before the above passage we write, "We maintain that the fact that there is no justifiable basis for the differential nature of the hypocrite's blaming disposition is the reason why the hypocrite's DBD is an instance of unfair exception-making that contravenes the equality of persons" (2018: 132, emphasis added). We leave it open that the Type B blamer's failure to blame consistently is due to either (i) some imperfect disposition to blame (though not grounded in unequal regard) or (ii) a disposition to blame consistently that is prevented from manifesting due to some other factor (e.g., forgetfulness, inattentiveness, etc.). Our view does not imply that the Type $\mathrm{B}$ blamer loses the standing to blame in either case. We maintain that, whatever explains why the Type B blamer fails to blame consistently, it is not due to a rejection of the impartiality of morality or the equality of persons (in contrast with Type A blamers). Thus, we leave it open that there are justifiable reasons for differential blaming in certain cases (2018: 213, n. 13). 
related. If such blamers are common, then we must accept that hardly anyone will have the standing to blame others. This sort of implication seems counterintuitive, and others, such as Bell (2013), use it to reject conditions on the standing to blame.

In response to the first question, we do not find it counterintuitive that Type A blamers lack the standing to blame the terrorists for their attacks-even in Todd's case. If the inconsistent blamer in Todd's case is of Type A, then presumably the inconsistency in her blame involves regarding the killing of US citizens or Westerners as somehow worse than killing Turkish citizens or Middle Easterners. ${ }^{18}$ Someone who rejects the equality of persons by regarding the murder of citizens of one nationality or ethnicity as a more serious wrong than the murder of citizens of another nationality or ethnicity does seem to lack the standing to blame a terrorist who murders citizens. If one's moral compass is so skewed that one regards other persons as morally unequal in virtue of their nationality or ethnicity, it does not sound so odd that such a person lacks the moral right to hold the terrorist accountable.

The claim that Type A blamers lack the standing to blame is further supported by the fact that it is commonplace to regard inconsistent blaming as analogous to hypocrisy, especially in politics (Fritz 2019: 322-323). For example, many conservative news outlets accused late-night talk show hosts of being hypocritical in not publicly blaming Harvey Weinstein for his alleged sexual assault and misconduct when they were so eager to blame Donald Trump, Bill O'Reilly, and other conservatives for allegations of sexual assault (Hanson 2017). On the other side of the aisle, Hillary Clinton has called the Trump administration's use of private email accounts for government business "the height of hypocrisy," given how willing they were to blame her for using such an account (Rawlinson \& Pengelly 2017). So, if hypocrisy undermines standing, and Type A blamers are relevantly analogous (as they are commonly taken to be), then the claim that Type A blamers lack standing is not implausible after all.

In any case, it is unclear how prevalent these kinds of Type A blamers are. Those who initially seem like Type A blamers might turn out, upon inspection, not to be Type A blamers after all. Consider the evidence that Todd's terrorist cites in his speech. He says that although many US citizens blamed terrorists for attacks in Orlando and Paris, they "hardly seemed to notice" the attacks in Turkey: "There was no general outpouring of grief for those who lost their lives,

18. On this way of interpreting the case, the Type A blamer is disposed to blame two violators of $N$ inconsistently because of who their respective victims are. If one thinks the victim of one wrongdoer matters less given who they are, for instance, then one might think that that wrongdoer's violation of $N$ is less wrong and therefore that less blame is deserved in this case. Alternatively, a Type A blamer might be disposed to blame one violator of $N$ and not another because of who the violator is. (This is the sort of Type A blamer we have in mind in Fritz \& Miller 2018: 131-132.) 
and no corresponding public anger with those who saw fit to take them" (Todd 2019: 369). ${ }^{19}$

There are a host of plausible reasons to explain this difference in overt blame that make no appeal to a UDBD. Perhaps US citizens did not express their emotions because they do not feel as strong of a connection with the people of Turkey. Humans have limited emotional resources and, for better or worse, we tend to be devoted to those with whom we feel a closer relationship. ${ }^{20}$ We need not see this as a rejection of the moral equality of persons. A father need not reject the moral equality of persons when he feels more affinity toward his own child than a stranger's child. And a mother is not unfairly inconsistently blaming when she publicly lashes out at a drunk driver who hits her child, even though she feels only a bit of indignation toward a drunk driver who hits the child of another person she reads about in the news.

Furthermore, even if US citizens lacked the emotional resources to be exercised enough to experience blame, they may still have been disposed to blame the terrorists consistently. So, simply because there was no public outcry over Turkey in the same way that there was over Orlando and Paris does not mean that US citizens had UDBDs. Similarly, the appearance of inconsistency does not establish a rejection of the equality of persons. Type A blamers who are disposed to blame inconsistently due to a UDBD rather than due to a lack of emotional resources, for instance, are likely rarer than one might think at first blush.

Even if Type A blamers are rare, the implication that Type A blamers lack the standing to blame may still seem counterintuitive. First, one might take this to imply that Type A blamers are as bad as hypocritical blamers. Indeed, Todd's reluctance to accept inconsistent blame as undermining standing could be rooted in the thought that hypocrisy is a worse fault than inconsistency. Todd envisions the terrorist accusing his imaginary interlocutor of hypocrisy by supporting the United States government, which itself engages in terrorism (2019: 370). Todd suggests that this speech is more challenging. But we can accept this. Perhaps it is worse to make an exception of yourself rather than of someone else, and this is why hypocrisy is a worse fault. As we write, "Although our view implies that the

19. It is odd that Todd's terrorist focuses on overt expressions of blame in attempting to determine whether US citizens have the standing to blame. As noted above, Todd narrows his focus to the "basic" standing to blame, or the standing to "feel" blame rather than "express" blame (2019: 350). It is possible that US citizens did experience indignation and moral anger upon learning of the attacks, but did not express those attitudes. Nevertheless, one might take the expression of blame as evidence that US citizens blamed the Orlando and Paris terrorists more than the Turkey terrorists. Though we have been focusing on inconsistent blamers who are unfairly disposed to blame one person and not another for violations of $N$, one might also be an inconsistent blamer if one is unfairly disposed to blame one person more than another for violations of $N$. We have ignored this complication of inconsistency in degree of blaming for ease of exposition.

20. Sher (2006: 89) also acknowledges this, though for a different purpose. 
hypocrite and inconsistent blamer each lack standing, it doesn't entail that their faults are equally morally objectionable" (2018: 132).

Second, the view that Type A blamers lack the standing to blame may be taken to imply that Type A blamers can never have the standing to blame. However, we emphasize that individuals can regain the standing to blame (2018: 130). Suppose that a Type A blamer recognizes that she has no good reason for blaming the terrorists for Paris and not for Turkey. If in recognizing her fault she sheds her UDBD, she now has the standing to blame the terrorists for both the Paris attack and the Turkey attack.

To review, Todd argues that our account has the counterintuitive implication that the inconsistent blamer would lack the standing to blame the terrorists in his imagined case. However, this is true only if the inconsistent blamer is a Type A blamer, in which case (we have argued) the implication is not counterintuitive after all. Furthermore, our view implies neither that inconsistent blame is as bad as hypocritical blame nor that such an agent cannot regain the standing to blame. In light of these considerations, Todd's criticisms of our account no longer seem forceful.

\subsection{Methodological Concerns}

The way Todd attempts to dismiss our view is itself suspect. First, much of the force of his argument comes from the intuition that the terrorist has some special moral authority over us, such that we are silenced because of his speech:

Unless we can answer the charge of being improperly differential in our dispositions to blame, must we simply walk away in silence after such a speech? Are we, effectively, silenced by the terrorists on the grounds that we do not react so negatively to other's [sic] terrorism? . . Frankly it seems bizarre to suppose that a terrorist may silence our criticism on grounds that we are-even wrongfully - not as disposed to blame others for their terrorism as we are now disposed to blame him for his. (2019: 369, emphasis original)

Todd's own italics suggest that part of what is so disturbing about this speech is that a terrorist, of all people, apparently has the authority to silence us in our blame.

On our view, people do not lose standing on the basis of the moral demands of others; they lose it simply because they have UDBDs. If we lack standing, according to our view, then we lack the standing before and independently of any such speech, and regardless of who makes it. It is worth asking whether the same speech can be made by a different individual rather than the terrorist while still 
having the same intuitive force. After all, the only role the terrorist plays here is to say something that is purportedly true. All that matters is what the terrorist points out, not that it is a terrorist who points it out. ${ }^{21}$

Todd's use of the terrorist making the speech seems to be an unfair intuition pump that contaminates the case. Indeed, throughout his paper Todd largely appeals to intuitions and imagined conversations between imaginary interlocutors. While these intuition pumps and conversations are a useful first step in making an argument, they should pave the way for a more structured or detailed argument, and this is precisely what Todd fails to offer.

As laid out in Section 1, we offer an argument for the conclusion that the would-be hypocritical blamer lacks the standing to blame for certain norm violations (2018: 125). A parallel argument also goes through for the Type A inconsistent blamer, who also has a UDBD.

Essentially, Todd attempts to dismiss our view via a reductio: if our view has this purportedly absurd conclusion, it must be false. Above we have shown that it is not at all clear that our view has the absurd conclusion Todd thinks, and that the implications that our view may have are not very counterintuitive after all. Yet if an argument's conclusion does have a false or implausible implication, one should return to the argument and determine which premise should be rejected. Given that our argument is valid, the conclusion is false only if one of the premises is false. Yet Todd does not tell us which premise he rejects or why.

Although he does not engage with the argument, Todd claims that our account goes wrong in its failure to distinguish between "lacking a right (or an entitlement) and being disposed to exercise that right (or entitlement) unfairly" (2019: 370). Todd describes two colleagues, Ellie and Suilin, who fail to respond to emails in a timely fashion (though Todd himself is prompt in responding to emails). When Todd confronts Ellie about her lack of response to an email, she could claim that Todd is not disposed to blame Suilin as well, so he has no right to blame her. Alternatively, she could claim that Todd is not disposed to blame Suilin, so he is exercising his right unfairly. The second response, says Todd, is stronger (2019: 370).

It is unclear what Todd's complaint is. One possible interpretation is that Todd believes that we hold the following view:

21. Notably, an anonymous referee for Noûs makes a similar point, which Todd acknowledges in a footnote. The referee suggests that a genuinely concerned third party making the speech seems to have more merit. Todd simply disagrees without offering an explanation-perhaps assuming that the intuition pump works the same in both cases. But it is not at all obvious that it does, and if it does, it would be more responsible to use the third party without italics to elicit the same intuition. 
DE: Being disposed to exercise one's right to blame unfairly entails that one lacks the right to blame.

DE is incoherent: it implies that one could simultaneously have the right to blame and also not have that right. Yet we do not endorse DE, but this view:

DB: Being disposed to blame unfairly entails that one lacks the right to blame.

DB is perfectly coherent. Compare the following two claims:

(1) Unless one is disposed to exercise one's moral right to administer capital punishment fairly, one does not have the moral right to administer capital punishment.

(2) Unless one is disposed to administer capital punishment fairly, one does not have the moral right to administer capital punishment.

While (2) is plausible, (1) is not. And (2) is analogous to DB. So if Todd understands our view as $\mathrm{DE}$ rather than $\mathrm{DB}$, he simply misunderstands our view. ${ }^{22}$

In any case, Todd does not explain how the distinction between lacking a right and being disposed to exercise that right fairly bears on the truth of one of the premises of our argument. (And given that our view is DB, not DE, it is not clear why this is where we go wrong, if we do.) In fact, we can happily acknowledge this general distinction. However, we offer an argument for the claim that, when it comes to the right to blame, the latter entails the former: the disposition to blame unfairly entails the lack of the right to blame.

Todd has not explained why (or how) one could have the standing or right to blame even though one is unfairly disposed to blame. We have given a valid argument showing that in having an unfair differential disposition to blame one thereby forfeits the right to blame. Thus, Todd has given no reason to reject our argument or view.

\subsection{The Shortcomings of Todd's View}

There are good reasons to reject Todd's own view. According to Todd, "one has standing if and only if one is morally committed to the values that condemn the wrongdoer's actions" (2019: 357). Todd does not clearly explain what a commitment to morality involves. All he offers is that "the sort of commitment at

22. Thanks to an anonymous referee for pointing out this possible confusion and for offering the helpful capital punishment example here. 
issue . . consists, minimally, in endorsement of the value as a genuine value, together with at least some degree of motivation to act in accordance with the value" (2019: 355). There are two problems with this understanding.

First, the hypocritical blamer can be committed to morality in the way Todd requires. The hypocritical blamer's blame (unless it is hollow or fake) involves a normative or value judgment that requires an endorsement of the relevant norm or value. Furthermore, nothing precludes the hypocritical blamer from having "at least some degree of motivation to act in accordance with the value," even if she never in fact does. Since the hypocritical blamer can meet Todd's minimal requirements, Todd has failed to identify a sufficient condition on standing. Presumably, Todd thinks that whatever commitment the hypocritical blamer may have to the relevant value is insufficient. But then he needs to further develop his account to specify what degree or kind of commitment to morality is sufficient for having the standing to blame.

Second, there is nothing about the nature of the Type A inconsistent blamer that involves a greater commitment to morality than the hypocritical blamer. They both are what they are in virtue of a UDBD - a disposition to unfairly make exceptions in their blaming. For this reason, both the hypocritical blamer and the Type A inconsistent blamer can endorse some value and be motivated to uphold it to some degree. Todd's view seems to imply that whatever kind of lack of commitment to morality it is that undermines the hypocritical blamer's standing to blame (supposing he specifies what exactly this is) will do the same for Type A inconsistent blamers. Ironically, this implication is the very reason that he rejects our account of why would-be hypocritical blame undermines the standing to blame. In order to avoid this implication, Todd must explain why the hypocritical blamer's lack of commitment to morality is relevantly different from that of the Type A inconsistent blamer.

After rejecting our grounding for the Nonhypocrisy Condition on standing, Todd admits that he has no explanation or grounding for the condition himself, and consequently no answer to Bell's challenge. The reason Todd lacks an explanation seems obvious. He has not identified the right feature to explain the unique badness of hypocritical blame. No one is perfectly committed to morality in the right way, as Todd points out. Yet we do explain the sort of commitment to morality that is required: respect for the moral equality of persons. This explanation can do the deeper work required and it is more illuminating than Todd's deflated answer, which we imagine many will find unsatisfying. 


\section{Conclusion}

As we have seen, though several accounts aim to explain how or why hypocrisy can undermine the standing to blame, only our account provides a plausible explanation. While some have attempted to cast doubt on the viability of our view, such attempts fall short. Rejecting the equality of persons with respect to some norm is necessarily a constitutive part of would-be hypocritical blame for violations of that norm, and thus provides the fundamental explanation for why the would-be hypocritical blamer lacks the standing to blame for violations of that norm. Crucially, our argument does not have the counterintuitive implications Todd suggests. Only inconsistent blamers of a very special sort will lack the standing to blame, and this result fits well with our intuitions and everyday practices. As a result, ours remains the best account on offer.

Of course, the best account on offer is not necessarily the correct one. Perhaps a better account is forthcoming. ${ }^{23}$ But this will be challenging. Offering an alternative to our account requires at least two tasks. First, one must show which premise in our argument is false and why. One might think, for instance, that the right to blame is not grounded in the equality of persons. To make a compelling case, however, one would have to explain what grounds the right to blame if not the equality of persons. Second, one must offer an alternative positive account that answers Bell's challenge and explains why hypocritical blame is standingless blame. Given the power of our argument, this alternative must either do a better job accounting for the facts or have fewer (or less problematic) counterintuitive implications. Without any such alternative, one should prefer our view.

\section{Acknowledgments}

We would like to thank Patrick Todd, Taylor Cyr, and Philip Swenson for helpful comments on an earlier version of this paper. We would especially like to thank Steve McFarlane for valuable feedback and conversations on this paper.

\section{References}

Bell, Macalester (2013). The Standing to Blame: A Critique. In D. Justin Coates and Neal A. Tognazzini (Eds.), Blame: Its Nature and Norms (263-281). Oxford University Press. https://doi.org/10.1093/acprof:oso/9780199860821.003.0014.

Cohen, G. A. (2012). Ways of Silencing Critics. In Michael Otsuka (Ed.), Finding Oneself

23. For example, Rossi (2018) offers a rival account of hypocrisy and claims that it can explain why all hypocrites lack the standing to blame. However, Rossi has yet to produce that argument. 
in the Other (134-142). Princeton University Press. https://doi.org/10.23943/princeton/9780691148809.003.0007.

Correal, Annie, and Joseph Goldstein (2019, February 9). 'It's Cold as Hell': Inside a Brooklyn Jail's Weeklong Collapse. The New York Times. Retrieved from https:// www.nytimes.com/2019/o2/og/nyregion/brooklyn-jail-no-heat-inmates.html

Duff, R. A. (2010). Blame, Moral Standing, and the Legitimacy of the Criminal Trial. Ratio, 23(2), 123-140. https://doi.org/10.1111/j.1467-9329.2010.00456.x.

Fritz, Kyle G. (2019). Hypocrisy, Inconsistency, and the Moral Standing of the State. Criminal Law and Philosophy, 13(2), 309-327. https://doi.org/10.1007/s11572-018-9472-y.

Fritz, Kyle G. and Daniel Miller (2018). Hypocrisy and the Standing to Blame. Pacific Philosophical Quarterly, 99(1), 118-139. https://doi.org/10.1111/papq.12104.

Fritz, Kyle G. and Daniel J. Miller (2019). When Hypocrisy Undermines the Standing to Blame: A Response to Rossi. Ethical Theory and Moral Practice 22(2): 379-384. https:// doi.org/10.1007/s10677-019-09997-3

Hanson, Hilary (2017, October 10). Late Night Hosts Slammed for Relative Silence on Weinstein Allegations. Huffington Post. Retrieved from https://www.huffingtonpost. com/entry/harvey-weinstein-allegations-late-night_us_59d8f10fe4b072637c446031

Isserow, Jessica and Colin Klein (2017). Hypocrisy and Moral Authority. Journal of Ethics and Social Philosophy, 12(2), 191-222. https://doi.org/10.26556/jesp.v12i2.224.

Scanlon, T. M. (2008). Moral Dimensions: Permissibility, Meaning, Blame. Harvard University Press. https://doi.org/10.4159/9780674043145.

Sher, George (2006). In Praise of Blame. Oxford University Press. https://doi.org/10.1093/ 0195187423.001.0001.

Sher, George (2013). Wrongdoing and Relationships: The Problem of the Stranger. In D. Justin Coates and Neal A. Tognazzini (Eds.), Blame: Its Nature and Norms (49-65). Oxford University Press. https://doi.org/10.1093/acprof:oso/9780199860821.003.0003.

Rawlinson, Kevin and Martin Pengelly (2017, September 26). 'Height of Hypocrisy': Clinton Calls Out Trump Team over Private Email Reports. The Guardian. Retrieved from https://www.theguardian.com/us-news/2017/sep/26/ivanka-trump-jared-kushnerstaff-private-email-official-white-house-work

Roadevin, Cristina (2018). Hypocritical Blame, Fairness, and Standing. Metaphilosophy, 49(1-2), 137-152. https://doi.org/10.1111/meta.12281.

Rossi, Benjamin (2018). The Commitment Account of Hypocrisy. Ethical Theory and Moral Practice, 21(3), 553-567. https://doi.org/10.1007/s10677-018-9917-3.

Todd, Patrick (2019). A Unified Account of the Moral Standing to Blame. Noûs, 53(2), 347-374. https://doi.org/10.1111/nous.12215.

Wallace, R. Jay (2010). Hypocrisy, Moral Address, and the Equal Standing of Persons. Philosophy and Public Affairs, 38(4), 307-341. https://doi.org/10.1111/j.10884963.2010.01195.x. 